\title{
GAIKÔGO: AS PALAVRAS JAPONESAS QUE SE TORNARAM ESTRANGEIRAS
}

Tatsuo Miyajima

\section{Definição de Gaikôgo}

Os estrangeirismos de origem ocidental(gairaigo) ocupam um espaço importante dentro da língua japonesa, onde aumentam a cada ano nos últimos tempos. A divisão do léxico japonês em três grupos, ou seja, de origem japonesa, chinesa e ocidental (wago, kango e gairaigo, respectivamente), é natural na língua japonesa, mas não é apropriada para outras línguas. Tanto no inglês quanto no chinês, a classificação mais corrente é a de nomes próprios e estrangeirismos. Gairaigo, na língua japonesa, refere-se a palavras de origem européia, e trata-se de empréstimos ou um tipo de estrangeirismos no sentido amplo. Sendo assim, Gairaigo, no sentido amplo, inclui o Kango:

Gairaigo - estrangeirismos no sentido amplo = empréstimos:

- Kango - estrangeirismos provenientes da língua chinesa

-Gairaigo estrangeirismos no sentido estrito = estrangeirismos de línguas ocidentais

1. Atualmente membro honorário do Japanese Language National Institute (Kokuritsu Kokugo Kenkyûjo), foi professor visitante junto ao Programa de Pós-Graduação em Língua, Literatura e Cultura Japonesa da Faculdade de Filosofia, Letras e Ciências Humanas da Universidade de São Paulo, em 2005. 
O termo shakuyô (empréstimo) é usado também no sentido monetário ou relativo a bens, mas o ato não implica redução de um lado por causa dos empréstimos ao outro, e nem há necessidade de devoluções. O empréstimo financeiro dos Estados Unidos para o Japão deve ser devolvido, mas os empréstimos lexicais (shakuyôgo), não.

Já o termo Gaikôgo é usado de forma restrita, mesmo entre os estudiosos da língua japonesa. É Miwa (1970) quem o usou pela primeira vez, ao afirmar: "No texto que se segue, gostaria de usar o termo Gaikôgo 'as palavras que vão para fora', em contraposição ao Gairaigo, 'as que vêm de fora"'

Gaikôgo é justamente o oposto do fato que ocorre com Gairaigo. A palavra table, do inglês, tornou-se têburu, fazendo parte do grupo de Gairaigo da língua japonesa. Por outro lado, a palavra japonesa tsunami "maremoto", tornou-se Gaikôgo, uma vez que passou a fazer parte do vocabulário do inglês. Os Gaikôgo, portanto, são palavras japonesas que se tornaram empréstimos em outras línguas. Neste artigo, passo a tecer considerações sobre as palavras de origem japonesa que se tornaram empréstimos, passando a fazer parte do vocabulário, especificamente, do inglês e do chinês.

\section{Gaikôgo: estrangeirismos japoneses na língua inglesa}

A língua inglesa é, nos dias de hoje, a que mais "exporta" suas palavras como empréstimos para as outras línguas do mundo todo. Não somente as línguas japonesa e coreana, mas também a alemã e a francesa têm buscado soluções para os empréstimos de origem inglesa, que aumentam progressivamente. Entretanto, historicamente, após a Idade Média, o inglês, que pertence ao grupo das línguas germânicas, importou em quantidade maciça o léxico das línguas francesa e latina, de línguas româmicas. Nesse ponto, assemelha-se às palavras chinesas na língua japonesa, mas em grau muito superior (cf. Bradley, 1982).

Ao compararmos os dicionários, Shinsen Kokugo Jiten, de língua japonesa, e Understanding English, de inglesa, temos a seguinte proporção de verbetes, divididos conforme a origem:

\begin{tabular}{|c|c|c|c|}
\hline \multicolumn{2}{|c|}{ Shinsen Kokugo Jiten } & \multicolumn{2}{|c|}{ Understanding English } \\
\hline \multicolumn{2}{|c|}{ (aproximadamente 87.000 verbetes) } & \multicolumn{2}{|c|}{ (aproximadamente 140.000 verbetes) } \\
\hline De origem japonesa: & $33,8 \%$ & De origem própria: & $14,0 \%$ \\
\hline De origem chinesa: & $49,1 \%$ & De origem latina: & $36,0 \%$ \\
\hline De origem ocidental: & $8,8 \%$ & De origem francesa: & $21,0 \%$ \\
\hline \multirow[t]{2}{*}{ De origem mista: } & $8,4 \%$ & De origem grega: & $4,5 \%$ \\
\hline & & Outros: & $24,5 \%$ \\
\hline
\end{tabular}


As palavras japonesas tiveram seu emprego como empréstimos na Europa no mesmo período em que houve a introdução de estrangeirismos de origem ocidental no Japão. Os jesuítas portugueses e espanhóis que chegaram ao Japão trouxeram as palavras como pan "pão" e kasutera "pão-de-ló", mas ao mesmo tempo, para apresentação de costumes japoneses aos seus respectivos países, adotaram os nomes em japonês que designavam objetos e fatos próprios do Japão. As palavras japonesas adotadas no inglês, na primeira fase, também tiveram como intermediário o português e o espanhol. A seguir, citaremos os verbetes de origem japonesa, incorporados no dicionário The Oxford English Dictionary, em ordem cronológica crescente do ano da inserção. Apresentamos primeiramente o ano da inserção do verbete no referido dicionário, seguido do verbete em questão, da palavra em japonês escrita em ideogramas ou fonogramas, da leitura atual em japonês, e finalmente sua tradução ou explicação em português ${ }^{2}$ :

1588, bonze [坊主] bôzu, bonzo

1613, katana [刀] katana, espada

1614, tatami [畳] tatami, tatame

1616 , kobang [小判] koban, moeda antiga de outro ou prata, em formato oval

1616, mochi [餅] mochi, bolo de arroz do tipo moti

1616, samisen [三味線] shamisen, instrumento musical tradicional de três cordas 1620, tai [鯛] tai, pargo

1677, moxa [もぐさ] mogusa, moxabustão

1679 , soya [しょうゆ] shôyu, molho de soja

1727, Shinto [神道] shintô, xintoísmo

1727 , kaki [柿] kaki, caqui

1727, kana [仮名] kana, silabário japonês

1727 , katsuo [鰹] katsuo, bonito (peixe)

1727, koi [鮕] koi, carpa

1727, kuruma [車] kuruma, carruagem

1727, matsuri [祭 り] matsuri, festival

1727, mikado [帝] mikado, imperador

1727, samurai [侍] samurai, guerreiro

1727, satori [悟り] satori, iluminação espiritual

1727 , shoyu [しょうゆ] shôyu, molho de soja

1727 , tokonoma [床の間] tokonoma, espaço sagrado na sala de uma casa japonesa

1727, torii [鳥居] torii, portal xintoísta

1727, urushi [弓るし] urushi, laca japonesa

1727, zen [禅] zen, Zen Budismo

1795, koto [琴] koto, cítara japonesa

2. Traduções e explicações do tradutor. 
1822, habutai [羽二重] habutae, seda branca, tecida com fios de seda crua de forma especial

1822, yukata [浴衣] yukata, quimono informal de algodão para uso no verão

1857 , tycoon [大君] taikun, nome usado para se referir ao xogum, pelos estrangeiros, no período Edo

1874, jinrikisha [人力車] jinrikisha, riquixá

1875, shippo [七宝] shippô, cloisonné

1877, shiitake [椎茸] shiitake, cogumelo shiitake

1877 , tanka [短歌] tanka, poema curto de 5 versos com 5, 7, 5, 7, 7 sílabas, respectivamente

1879, ukiyo-ye [浮世絵] ukiyoe, pintura de xilogravura japonesa

1880 , happi [法被] happi, um tipo de capa, sem mangas, inicialmente usada pelos monges

1887 , rikisha [力車] rikisha, riquixá

1889, judo [柔道] jûdô, arte marcial judo

1890, miai [見合い] miai, encontro arranjado para fins de casamento

1893, gagaku [雅楽] gagaku, música tradicional e clássica da corte

1898, bushido [武士道] bushidô, conjunto de conduta dos samurais

1902, haiku [俳句] haiku, haicai, poema curso de 3 versos, com 5, 7 e 5 sílabas, respectivamente

1915, shimosite [下瀬火薬] shimosekayaku, pólvora Shimose

1920, narikin [成金] narikin, novo rico

1920, sukiyaki [すきやき] sukiyaki, cozido de carnes, cebolinhas e outros

legumes

1921, kendo [剣道] kendô, arte marcial de espada

1922, origami [折り紙] origami, dobraduras de papel

1937, zaibatsu [財閥] zaibatsu, conglomerado industrial

1943, nisei [二世] nissei, filho de pais japoneses, nascido na América

1947, tenko [点呼] tenko, chamada para verificar presença

1953, pachinko [パチンコ] pachinco, jogos eletrônicos como de caça-níqueis

1955, karate [空手] karate, arte marcial caratê

1958, emakimono [絵巻物] emakimono, rolos com desenhos

1959, kokeshi [こけし] kokeshi, bonecos tradicionais de madeira

1964, ninja [忍者] ninja, espiões do senhor feudal

1967, shiatsu [指圧] shiatsu, massagem com os dedos

1968, shinkansen [新幹線] shinkansen, trem-bala

1968, zaikai [財界] zaikai, círculo econômico, círculo financeiro

1970, kogai [公害] kôgai, poluição

1970, shabu-shabu [しゃぶしゃぶ] shabu-shabu, prato com carne em fatias

finas e verduras, cozidas mergulhadas em caldo quente, acompanhadas de molhos e especiarias 
1970, teppan-yaki [鉄板焼き] teppan-yaki, carne ou frutos do mar e verduras preparados na chapa

1971, sokaiya [総会屋] sôkaiya, membro de uma corporação extorsionária, que participa das assembléias de acionistas

1972, ramen [ラーメン] râmen, macarrão ensopado, tipo chinês

1976, shosha [商社] shôsha, firma

1979, karaoke [カラオケ] karaoke, karaokê

Dentre os verbetes citados, destaca-se a introdução considerável dos mesmos em 1727, ano da edição de Nihonshi "The History of Japan" de Kämpfer ${ }^{3}$, onde eram citadas as palavras japonesas em abundância, fara retratar a realidade própria do país.

Sobre os verbetes de origem japonesa que estão dentro da língua inglesa no período relativamente recente (1963-1987), Algeo (1997) tem mostrado o quadro seguinte, em que os números representam a proporção de cada grupo dentre os estrangeirismos, cuja ordem se baseia na média de quatro fontes:

\begin{tabular}{|l|l|l|l|l|l|}
\hline & $(1)$ & $(2)$ & $(3)$ & $(4)$ & ordem \\
\hline French & 31,4 & 17,5 & 21,2 & 12,0 & $1^{\circ}$ \\
\hline Spanish & 6,6 & 10,8 & 6,1 & 12,7 & $2^{\circ}$ \\
\hline Russian & 3,4 & 5,4 & 2,1 & 24,1 & $3^{\circ}$ \\
\hline Japanese & 7,9 & 9,3 & 6,3 & 9,0 & $4^{\circ}$. \\
\hline
\end{tabular}

(1)The Barnhart Dictionary of New English since 1963 (1973)

(2)The Second Barnhart Dictionary of New English(1980)

(3)The 1981 addenda to Webster's Third New International Dictionary, Unabridged

(4)The Barnhart Dictionary Companion Index(1987)

Seguem-se, abaixo da língua japonesa, posicionada em $4^{\circ}$ Lugar, $5^{\circ}$ língua africana, $6^{\circ}$ italiano, $7^{\circ}$ alemão, $8^{\circ}$ grego, $9^{\circ}$ latim, $10^{\circ}$ iídiche, $11^{\circ}$ árabe, $12^{\circ}$ chinês, chegando até $29^{\circ}$ esquimó, que são omitidos neste trabalho. Algeo afirma que, se a proporção anormal de palavras russas na fonte (4) for corrigida, o russo passaria a ocupar a $12^{\mathrm{a}}$. posição após árabe e chinês. Assim sendo, o japonês ocuparia a $3^{\mathrm{a}}$. posição, após francês e espanhol. Se levarmos em consideração o peso do francês, tradicional, e a quantidade expressiva dos falantes de espanhol nos Estados Unidos, esse é um fato que merece atenção.

3. N. do T. Engelbert Kämpfer (1651-1716). Médico alemão, viajante, tornou-se médico da Companhia das Índias Orientais e chegou a Nagasaki, Japão, em 1690, e visita a então capital Edo em 1691 e 92. Tendo como assistente um tradutor japonês, estuda a política, sociedade, costumes, indústria, fauna, flora e minerais do Japão. Sua obra Nihonshi, em versão inglesa, foi publicada postumamente, em 1727. 
Entretanto, ainda que a inserção do japonês na língua inglesa esteja alicerçada no registro de verbetes nos dicionários comuns do inglês, sendo este um critério adequado, há casos de alteração semântica, mesmo com a manutenção da forma. A palavra hibachi(braseiro) nos Estados Unidos e Canadá apresenta até sua forma no plural, hibachis, mas refere-se à chapa de ferro para preparar barbacoas.

Ainda, apresentam-se problemas também quanto ao grau de compreensão de tais palavras. Segundo Long (1997), sushi é um vocábulo conhecido pela maioria das pessoas, mas quase $80 \%$ das mesmas acreditam tratar-se de sashimi, enquanto apenas $20 \%$ sabem o que é sashimi, deixando dúvidas quanto à capacidade de distinguirem sushi e sashimi. Também ninja é bastante conhecido, mas muitos pensam tratar-se de guerreiro japonês. Dizem que zen e shinto, bonsai(cultivo de árvores em miniatura) e banzai(Viva!) também são freqüentemente confundidos. Sendo assim, seriam possíveis, entre os americanos, frases como: "No sushi de ontem, havia arroz, mas no de hoje não há" ou "Durante a guerra, os soldados japoneses avançavam gritando: 'Bonsai!'”

\section{Gaikôgo: estrangeirismos japoneses na língua chinesa}

No Japão antes da era Moderna, o texto formal era escrito em chinês(kanbun). Utilizando-se dos recursos de okurigana e kaeriten ${ }^{4}$, os japoneses de então liam-no em japonês, mas o texto formal, escrito em chinês arcaico, era também passível de leitura pelos chineses e coreanos, como os Anacletos de Confúcio e Shiki, de Shiba Sen. Um intelectual japonês do período Edo lia livremente os textos chineses arcaicos tal como um chinês, usando o método de kanbunkundoku, próprio do Japão, e ainda escrevia com facilidade nessa língua.

Os japoneses, no processo de absorção da cultura moderna do Ocidente, não somente introduziu os estrangeirismos, mas também criaram novas palavras ao estilo chinês(kango) para transmitir seu significado. É natural que nesse processo houvesse muitas tentativas de criação lexical, como se podem ver nos exemplos abaixo mencionados. Antes de chegar aos nomes utilizados hoje, como terebi, para televisão, e minshu shugi, para democracia, foram criados inúmeros itens lexicais, listados em respectivas colunas abaixo, com ano da criação e tradução literal:

4. N.de T. Okurigana eram as partes flexionáveis por exemplo de verbos, escritas em silabários, e kaeriten eram sinais que indicavam a inversão de ordem sintática, uma vez que a ordem da língua chinesa diferia da japonesa. Ambos os recursos eram utilizados pelos japoneses para auxiliar na leitura de textos chineses, leitura esta chamada de kanbunkundoku "leitura japonesa de textos chineses" 


\begin{tabular}{|c|c|}
\hline $\begin{array}{l}\text { テレビ terebi } \\
\text { "televisão" }\end{array}$ & $\begin{array}{l}\text { 民主主義 minshu shugi } \\
\text { "democracia" }\end{array}$ \\
\hline $\begin{array}{l}\text { 1930電視 denshi } \\
\text { "imagem elétrica" }\end{array}$ & $\begin{array}{l}1862 \text { 共和政治 kyôwa seiji } \\
\text { "regime republicano" }\end{array}$ \\
\hline $\begin{array}{l}1931 \text { 電気透視 denki tôshi } \\
\text { "imagem transparente elétrica" }\end{array}$ & $\begin{array}{l}1873 \text { 民政 minsei } \\
\text { "governo do povo" }\end{array}$ \\
\hline $\begin{array}{l}1931 \text { 無線電視 musen denshi } \\
\text { "imagem elétrica sem fio" }\end{array}$ & $\begin{array}{l}1885 \text { 民主政治 minshu seiji } \\
\text { "regime democrático" }\end{array}$ \\
\hline $\begin{array}{l}1931 \text { 電望 denbô } \\
\text { “imagem elétrica à distância" }\end{array}$ & $\begin{array}{l}1892 \text { 民治政体 minji seitai } \\
\text { "sistema de governo do povo" }\end{array}$ \\
\hline $\begin{array}{l}1931 \text { 無線遠視 musen enshi } \\
\text { "imagem à distância sem fio" }\end{array}$ & $\begin{array}{l}1914 \text { 民政主義 minsei shugi } \\
\text { "princípios do governo do povo" }\end{array}$ \\
\hline $\begin{array}{l}1931 \text { 電送活動写真 densô katsudô } \\
\text { shashin } \\
\text { "fotos vivas teletransportáveis" }\end{array}$ & $\begin{array}{l}1924 \text { 民本主義 minpon shugi } \\
\text { "principios do governo com base no povo" }\end{array}$ \\
\hline $\begin{array}{l}1933 \text { 実景電送映画 jikkei densô } \\
\text { shashin } \\
\text { "filme teletransportável com paisagem } \\
\text { real" }\end{array}$ & $\begin{array}{l}\text { 1926民主主義 minshu shugi } \\
\text { "princípios do povo como principal } \\
\text { (democracia)" }\end{array}$ \\
\hline \multirow[t]{4}{*}{$\begin{array}{l}1935 \text { 無線電送活動写真 musen densô } \\
\text { katsudôshashin } \\
\text { "fotos vivas teletransportáveis sem fio" }\end{array}$} & $\begin{array}{l}1931 \text { 貴賎無差別 kisen musabetsu } \\
\text { "Sem discriminação entre nobres e plebeus" }\end{array}$ \\
\hline & $\begin{array}{l}\text { 1931万民平等 banmin byôdô } \\
\text { "igualdade entre os 'dez mil povos"” }\end{array}$ \\
\hline & $\begin{array}{l}1931 \text { 民主 minshu } \\
\text { "povo como principal" }\end{array}$ \\
\hline & $\begin{array}{l}1934 \text { 民主制 minshusei } \\
\text { "sistema democrático" }\end{array}$ \\
\hline
\end{tabular}


No período pós-Guerra Sino-Japonesa, estudantes chineses afluíram no Japão não somente para conhecer a cultura japonesa, bem como para ter fácil acesso à civilização ocidental moderna. Muitos livros foram traduzidos nessa época para o chinês, ocasionando na língua chinesa a introdução do léxico ao estilo chinês ( $k a n g o$ ) criado no Japão. Porém, por volta de 1920 , esse movimento cessou, uma vez que a criação de kango no Japão foi substituída pela introdução de estrangeirismos de origem ocidental (gairaigo), e a China passou a traduzir os livros diretamente do Ocidente, sem o intermédio do Japão.

Citamos, a seguir, alguns exemplos de palavras ao estilo chinês (kango), criadas no Japão, que passaram a fazer parte do léxico chinês:

A) Palavras criadas pelos japoneses:

哲学 tetsugaku “filosofia", 科学 kagaku "ciência", 美術 bijutsu "artes, belas-artes", 抽象 chûshô "abstrato", 客観 kyakkan "objetivo", 否定 hitei "negação", 動員 dôin "mobilização", 不動産 fudôsan “imóvel", 個人 kojin "indivíduo", 体系 taikei "sistema", 本能 honnô "instinto"

B) Palavras chinesas antigas, reutilizadas pelos japoneses, com significado moderno: 革命 kakumei "revolução", 文化 bunka "cultura", 経済 keizai "economia", 共和 kyôwa "república", 関 係 kankei "relação", 破産 hasan "falência", 衛生 eisei "higiene", 社会 shakai "sociedade", 影響 eikyô “influência", 政治 seiji "política", 存在 sonzai "existência"

C) Palavras japonesas, mas associando leitura chinesa:

場合 baai “caso", 取締 torishimari “fiscalização/controle", 手続 tetsuzuki “procedimento/processo"

\section{Estrangeirismos japoneses na língua portuguesa}

Entre os que foram introduzidos ao português, há os que são comuns no inglês, tais como cabuqui, nô, caratê, judô, go, gueixa, micado, daimio, samurai, ninja, catana, tsunami, kamikaze, ikebana, que podem ser, alguns, mais antigos do que no inglês.

Dentre os pertencentes ao léxico relacionado à alimentação, há sashimi, sushi, saquê, sukiyaki, yakisoba, tempura, cabocha, kinoko e caqui.

Entre estes, há aqueles usados no cotidiano, sem saber que se tratam de palavras de origem japonesa. É uma tarefa importante investigar as condições atuais de uso, incluindo:

mapeamento de quais palavras são conhecidas (e por quem);

verificação de diferenças regionais no uso;

- conhecimento ou não da etimologia japonesa;

- alteração semântica dos estrangeirismos japoneses; 
- grau de uso dos mesmos na língua escrita do português;

- mapeamento de registros em dicionários (Japonês-Português, Português- Japonês, Português-Português e Português-Inglês).

\section{O futuro dos estrangeirismos japoneses}

Como seria o futuro dos estrangeirismos japoneses?

As considerações anteriores apontam que os estrangeirismos japoneses no inglês dos Estados Unidos, apesar de serem numericamente menores, colocam-se na posição relativamente alta. Ao levar em consideração a relação entre os Estados Unidos e Japão, esta tendência poderá continuar. Porém, o que é mais certo é que os estrangeirismos do inglês irão entrar com uma força preponderante na língua japonesa. Apesar dos movimentos parciais contrários, consideramos ser bastante dificil deter o processo.

A relação com a língua chinesa se distingue do inglês. Principalmente na tha Formosa, as palavras japonesas como

出張 shutchô "viagem a trabalho", 都合 tsugô “conveniência", 勘定 kanjô “conta", 料理 ryôri "cozinha/pratos", 弁当 bento "lanche/marmita"

foram introduzidas no período colonial, mas, recentemente, palavras como

外食 gaishoku “refeição fora de casa", 民宿 minshuku “hospedaria", 花火 hanabi “fogos de artifício", 人気 ninki "popularidade" e 不倫 furin "adultério"

têm sido absorvidas como estrangeirismos, além da aceitação de afixos como ya, - zoku, cuja alta produtividade na formação de palavras tem sido observada. Dentre esses estrangeirismos, há os que se inseriram no léxico do próprio continente chinês. Na medida em que se aprofunda o intercâmbio com outros países asiáticos, podese prever também influência na língua coreana e outras.

No Brasil, terminou a introdução da língua japonesa que acompanhou os imigrantes, mas gostaria de analisar se os grupos de dekassegui levam de volta ao Brasil a língua japonesa ou não.

\section{Bibliografia}

ALGEO, J. Vocabulary. The Cambridge History of the English Language. Vol. IV (1776-1997), Cambridge U.P. , 1997.

BRADLEY, Henry (trad. Yoshio Terasawa). Eigo hattatsu Shôshi "Pequena história da evolução de língua inglesa" Tóquio: Iwanami, 1982.

CANNON, Garland. The Japanese Contributions to the English Language. Harrasowitz,1996. 
HAYAKAWA, Isamu. Eigoni haitta nihongo goino shoshutsunen chôsa "Pesquisas sobre o anos iniciais da introdução de palavras japonesas no léxico inglês". Nihongo Kagaku "Ciência da Língua Japonesa", No. 13. Tóquio: Kokuritsu Kokugo Kenkyûjo, 2003.

KATO, Hidetoshi e KUMAKURA,Isao (org.). Gaikokugo ni Natta Nihongono Jiten "Dicionário da língua japonesa que se tornou estrangeira" Tóquio: Iwanami, 1999. LONG, Daniel. Gaikôgo ni taisuru amerikajinno ishikito sono shiyô "A consciência e o uso dos americanos com relação aos estrangeirismos japoneses" Material apresentado para o $66^{\circ}$ Encontro do Grupo de Estudos da Teoria de Variação, 1997.

MATSUDA, Yutaka. Nichieigono kôryû " $\mathrm{O}$ intercâmbio entre as línguas japonesa e inglesa" Tóquio: Kenkyusha, 1991.

MIWA, Takuya. Kyûsei Nihongo - Seiyôgoni okeru nihongo yuraino shakuyôgo "Antigas palavras japonesas - Os empréstimos de origem japonesa nas línguas ocidentais" Gengo seikatsu. Edição meses de janeiro-abril. Tóquio, 1970.

REIMAN, Etsuko Obata. Tobeishita nihongo - gaikanto shiryô "A língua japonesa que viajou para os Estados Unidos - Considerações gerais e dados" Nihon Kindaigo Kenkyû 1 "Estudos da Língua Moderna Japonesa I", 1991.

SANETÔ, Keishû. Chûgokujin Nihonryûgakushi Zôhoban "A história dos chineses em estudos no Japão Ed. Ampliada" Tóquio: Kuroshio, 1970.

SHIN, Kokui. Kindai Nicchû Goi Kôryûshi "História Moderna de Intercâmbio dos Léxicos Chinês e Japonês" Tóquio: Kasama,1994.

(Tradução: Junko Ota - FFLCH/USP) 